\title{
Design and Analysis of Co-planar Waveguide Fed Circular Monopole Antenna for Ultra Wideband Application
}

\author{
Samom Jayananda Singh, Rajesh Kumar
}

\begin{abstract}
A Printed monopole antenna with coplanar waveguide (CPW)- fed having circular shape patch to met the Ultra Wideband technology whose bandwidth is greater than $500 \mathrm{MHz}$ is proposed in this article. To enhance the bandwidth co-planar ground plane plays a great role for a frequency band which belong to mid band for $5 G$ frequency spectrum. A good radiation pattern which is usually in 8shape can be achieved with this proposed antenna.
\end{abstract}

Keywords: Printed Monopole Antenna, UWB(Ultra Wideband), CPW (Co-Planar Waveguide)

\section{INTRODUCTION}

With the advancement of wireless Communication, the need of antennas is a must with the following characteristics like compact size, light weight, low cost and easy to install in planar and non planar surface. Printed antennas is one of the most fit for ultra wideband, broadband applications that have the merit of large impedance bandwidth and in terms of radiation pattern. Because of many features, ultra-wideband (UWB) antennas are conspicuousness and one of the best applications in the modern wireless technology. Most of the wireless system, like wireless LANs, ultra wideband (UWB) systems are able to operate in many frequency band with the advancement of printed antennas. Diversity technique can be employed by implementing the technique of printed antennas. Analysis of volcano smoke antenna is made suitable with the design wideband antenna. Quarter wavelength dimensions is best match for radiation body for lowest operating frequency [1]. A layer of magneto dielectric material over a printed monopole antenna can able to reach the Ultra wideband specification in the frequency range of 8 $\mathrm{GHz}$ to $18 \mathrm{GHz}$ [2]. For a proper wireless communication applications purpose antenna need to have a good radiation patterns, larger bandwidth, and non-dispersive behavior, low cost and compact in nature monopole antenna is the best option. When compared to wire antenna with planar antennas with respect to bandwidth and radiation pattern,

Manuscript received on June 21, 2021

Revised Manuscript received on June 28, 2021.

Manuscript published on June 30, 2021.

* Correspondence Author

Samom Jayananda Singh*, Department of Electronics and Communication Engineering, NERIST, Nirjuli (Arunachal Pradesh), India. Email: jayanandmetal.inc@gmail.com

Rajesh Kumar, Department of Electronics and Communication Engineering, NERIST, Nirjuli (Arunachal Pradesh), India. Email: rk@nerist.ac.in

(c) The Authors. Published by Blue Eyes Intelligence Engineering and Sciences Publication (BEIESP). This is an open access article under the CC BY-NC-ND license (http://creativecommons.org/licenses/by-nc-nd/4.0/) planar antennas is far more better than normal antennas which reduce the physical height of the antenna[3].Improvement of cutting edge technology gives a strong expansion in the research field of wireless communication. Various patch antennas of different dimension were initiated for stretching the impedance bandwidth[5]. One of the key elements in successful UWB system is the design of a compact UWB antenna with compact dimensions and proper characteristics providing wideband characteristic over the whole operating band. In 2002, Federal Communication Commission (FCC) share the frequency band from 3.1 to $10.6 \mathrm{GHz}$. With the use ultra-wideband (UWB) technology high data- rate wireless communication and imaging systems can be employed easily. Interference occur in between the systems (IEEE802.11a WLAN (5.15-5.825 GHz) and the IEEE802.16 WiMAX (3.3-3.6 GHz), and C-band system (3.7-4.2 GHz)) and UWB system can able to minimize the interference by notching those frequency band using UWB antennas. Various categories of slots in the patch and ground for printed antennas can achieve more resonant modes for high impedance bandwidth [6]. Printed Rectangular Monopole Antennas (PRMA) with single, dual and triple microstrip line feed are used to enlarge the impedance bandwidth. Effects of patch width variation along with its offset feed, leads to wideband antenna characteristics. The increase in bandwidth in the case of off-centered feed Printed Rectangular Monopole Antennas is from $1.7 \mathrm{GHz}(1.40-3.1 \mathrm{GHz})$ to 3.9 $\mathrm{GHz}$ (1.3-5.2 GHz); which is far better than single centrefeed PRMA[7]. To maintain a bandwidth of $8.4 \mathrm{GHz}(3 \mathrm{GHz}$ up to $11.4 \mathrm{GHz}$ ) with a return loss of less than $-10 \mathrm{~dB}$, a two steps and a circular slot is designed in printed monopole antenna. Band-notched can be upgraded with well fitting slot in the radiating patch, besides its gives a good radiation pattern[8].Printed monopole antenna with bevels in the patch and ground plane for maximizing the bandwidth within the frequency band from 3 to $15 \mathrm{GHz}$ is presented. Fluctuating the dimension of the bevels leads to further support the increased in the bandwidth [9]. CPW fed line with defective ground structure design in the printed monopole antenna for improving the bandwidth is introduced. Defective ground plane help in building up a non uniform current distribution in the ground plane, Improper distribution of current makes the capacitance and inductance changes with its characteristics[10].

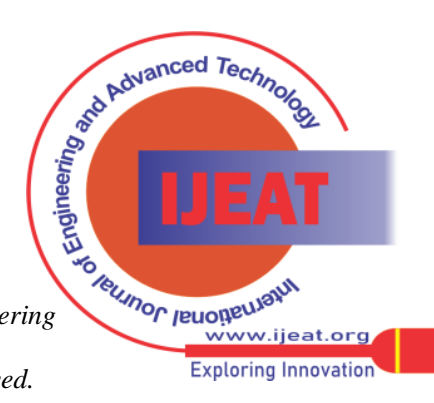


For obtaining a circular polarized antenna , a CPW fed planar monopole antenna designed with quadrilateral patch structure is employed. Inorder to have a proper impedance matching and improvement of bandwidth as well as for good gain array modification is done in[11]. Printed monopole antenna with the structure of ellipse shaped in the patch, containing various design of ground plane which include rectangular ,modified half circular, with sleeves is proposed. This method help in achieving a good bandwidth as well as improving the S-parameters characteristics[12]. In order to expand the bandwidth within the frequency range from $2.5 \mathrm{GHz}$ and $15 \mathrm{GHz}$, Printed monopole antenna with half elliptical patch shaped is designed. For further improvement of bandwidth can be obtained by cutting sectors slot on the patch. To acts as a filter, it is then making arc-shaped in the patch[13]. A 9 shaped patch structure printed monopole antenna which is suitable for Wifi and radio frequency identification (RFID) technologies is presented. For a better impedance matching ,truncated ground plane with fixed strip line is designed[14].Varying the feeding structure in a printed monopole antenna with Psi shaped patch can kept a good impedance bandwidth. Cutting of slot in the patch and ground plane upgrade the bandwidth up to a certain extent [15]. In [1] printed monopole antenna with trapezoid ground plane and an elliptical monopole patch fed by a modified tapered CPW line for a better bandwidth and good radiation pattern is proposed. Importance of coating of magnetodielectric material over a printed monopole antenna in broadening the bandwidth over a frequency range of $8-18 \mathrm{GHz}$ range is shown in [2].

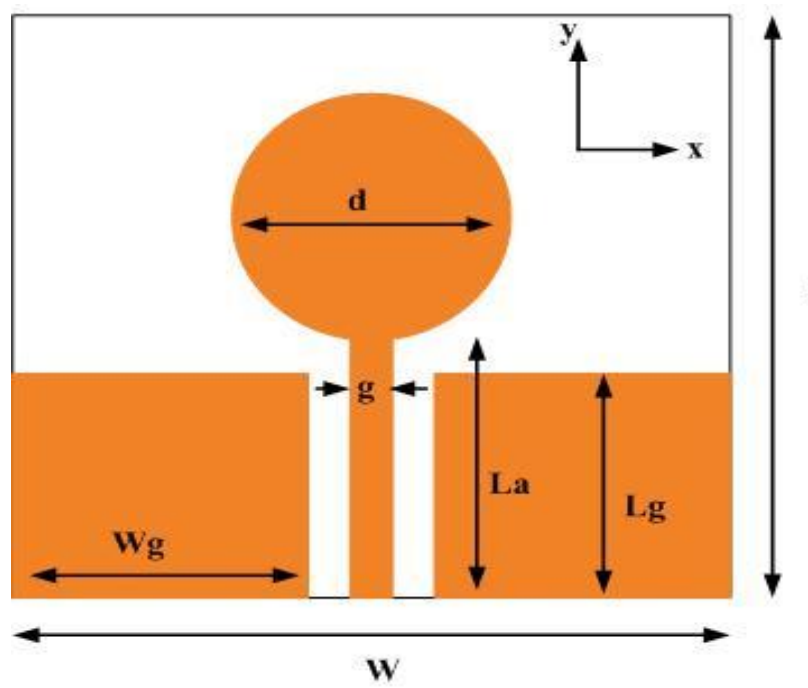

Fig1 Geometry of proposed antenna

\section{ANTENNA DESIGN}

The Design parameters were calculated from the wavelength $\left(\lambda_{L}\right)$ which corresponds to lower cut off frequency 3.1GHz[15].

Dimension of the monopole $(d)$,feed $\left(L_{a}\right)$ and feed gap has been calculated as per the following Equation1.

$$
\frac{\lambda_{L}}{8} \leq d \leq \frac{\lambda_{L}}{4}
$$

Effective length of the radiator is equal to the addition of the length of circular patch $(d)$ and the length of feed $\left(L_{a}\right)$.

$$
\left(d+L_{a}\right) \approx \frac{\lambda_{L}}{3}
$$

Difference of the feed length $\left(L_{a}\right)$ and the maximum length of co-planar ground plane $\left(L_{g}\right)$ is the feed gap. The optimal value of feed gap can be found out from the Equation 3.

$$
0.01 \lambda_{L} \leq\left(L_{a}-L_{g}\right) \leq 0.02 \lambda_{L}
$$

Dimension of dielectric substrate (L,W and h) of dielectric substrate FR-4 epoxy are selected in such a way that it should satisfied the following equation for 4 to 6 .

$$
\begin{aligned}
& \frac{\lambda_{L}}{4} \leq L \leq \frac{\lambda_{L}}{2} \\
& W=2 d \\
& h=0.01 \lambda_{L}
\end{aligned}
$$

Table 1:Proposed antenna Parameters

\begin{tabular}{|c|c|}
\hline Parameters & $\begin{array}{c}\text { Optimal dimension } \\
\text { value(mm) }\end{array}$ \\
\hline Length of substrate, $\mathrm{L}$ & 35 \\
\hline Width of substrate, $\mathrm{W}$ & 30 \\
\hline Substrate thickness, $\mathrm{h}$ & 0.8 \\
\hline Diameter of circular patch,d & 15 \\
\hline Ground Length. Lg & 15.9 \\
\hline Ground width, Lw & 30 \\
\hline Feed Length, La & 17.54 \\
\hline Feed width, g & 1.6 \\
\hline
\end{tabular}

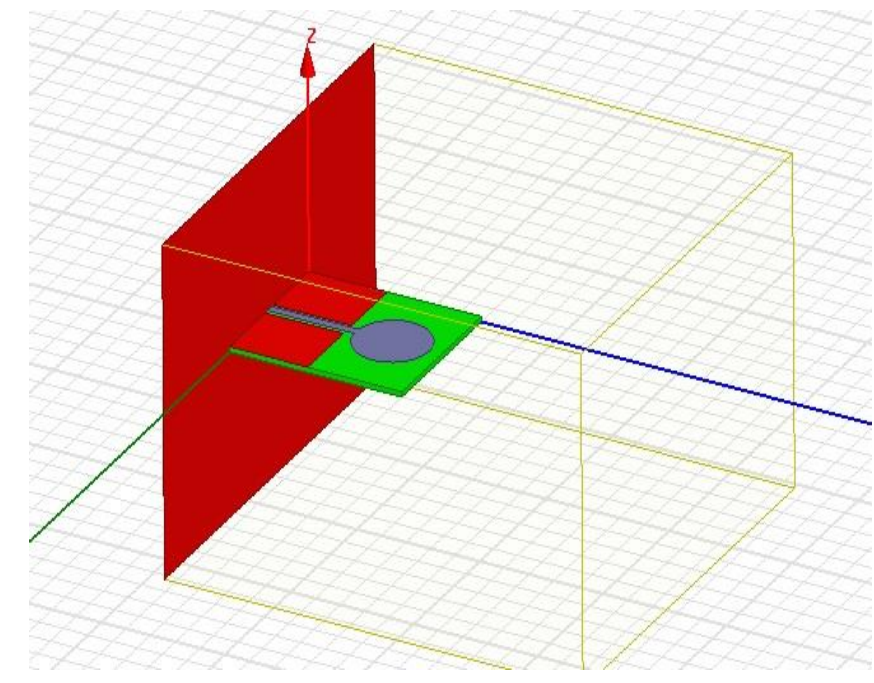

Fig2 Design of Proposed antenna using HFSS 18 version

The different parameters of the proposed antenna are calculate using the design relationship [10][12][15].

Published By:

Blue Eyes Intelligence Engineering and Sciences Publication

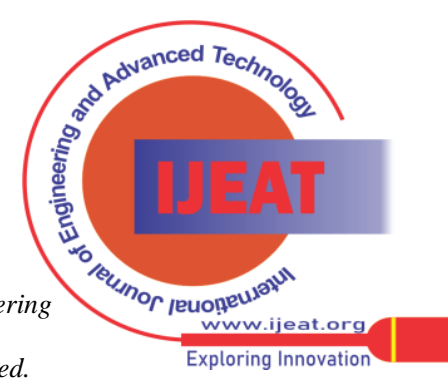




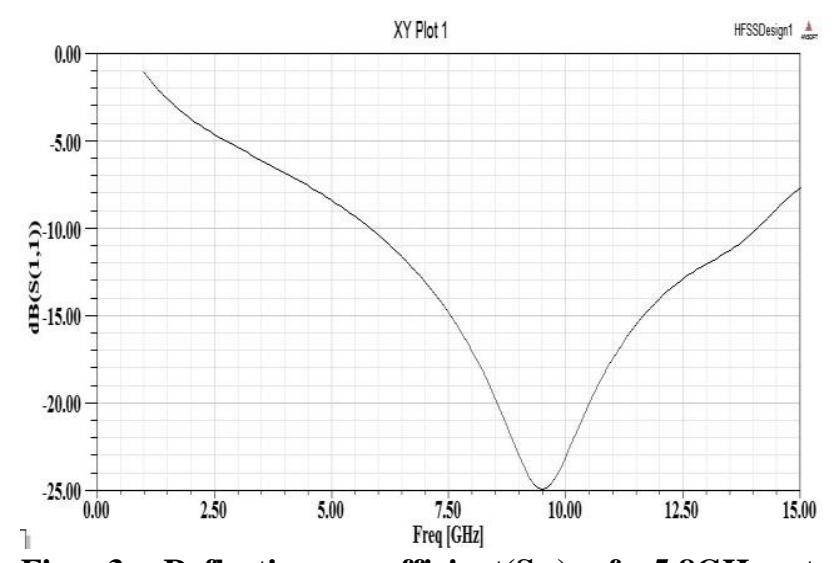

Fig 3 Reflection coefficient $\left(\mathrm{S}_{11}\right)$ for $5.8 \mathrm{GHz}$ to 14.10GHz

At $9.50 \mathrm{GHz}$ the designed single element has achieved $-24.52 \mathrm{~dB}$ return loss. The return loss $\mathrm{S}_{11}$ is below $-10 \mathrm{~dB}$ in the frequency band $5.8 \mathrm{GHz}$ to $14.10 \mathrm{GHz}$ shown in the graph Fig.3.

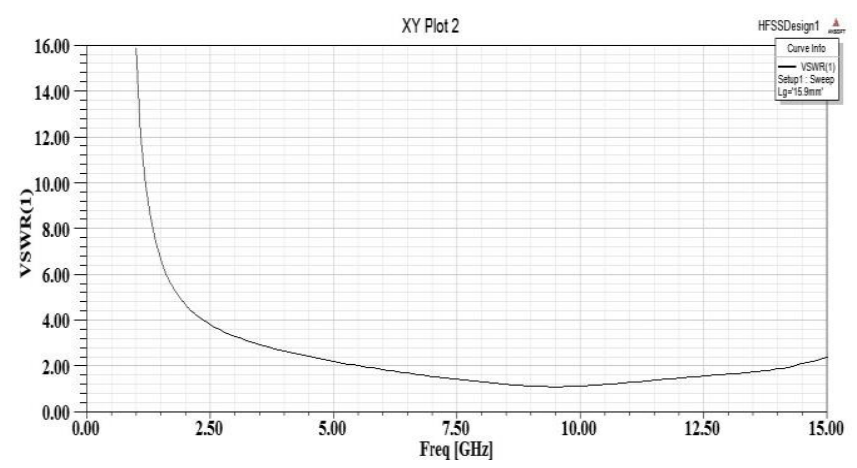

Fig 4 VSWR for $5.8 \mathrm{GHz}$ to $14.10 \mathrm{GHz}$

The voltage standing wave ratio (VSWR) of the designed antenna has achieved good results in the frequency band $5.8 \mathrm{GHz}-14.10 \mathrm{GHz}$ i.e. VSWR $\leq 2$ (5.8GHz-14GHz). At the center frequency, $9.50 \mathrm{GHz}$ the designed achieved VSWR value of 1.55 . Figure 4 VSWR graph shows that the designed antenna has well matched to the input impedance. The designed antenna VSWR result shows that the input port impedance is a well match

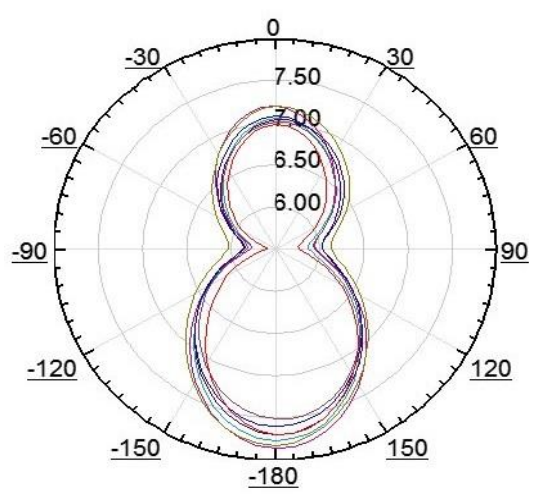

Fig 4 Radiation pattern of E plane

A Good radiation pattern which is usually 8 shape is observed in the E plane. From the graph it gives a better performance regarding the radiation pattern of the proposed antenna

\section{RESULT AND DISCUSSION}

The designed antenna array achieved return loss bandwidth of $26 \%$. The antenna array has achieved good return loss $\mathrm{S}_{11},-18.64 \mathrm{~dB}$ at $29.09 \mathrm{GHz}$ and VSWR $\leq 2$ $(5.81 \mathrm{GHz}-14.01 \mathrm{GHz})$. The designed array has return loss values $-10 \mathrm{~dB} \leq \mathrm{S}_{11} \leq-18.64 \mathrm{~dB}$ and achieved circularly polarized gain of $10.14 \mathrm{~dB}$. The designed array has wide bandwidth of return loss, VSWR and gain. So the designed can used for the mmWave wireless communication.

\section{CONCLUSION}

In this paper, $\mathrm{CPW}$ fed circular patch monopole antenna in the mid frequency range $(5.8 \mathrm{GHz}-15 \mathrm{GHz})$. To further enhance gain, metamaterial and superstrate should be used in the designed. The proposed antenna will be suitable for the future short range Wave wireless communication

\section{REFERENCES}

1. J. Liu, S. Zhong, and P. K Esselle,“A Printed Elliptical Monopole Antenna With Modified Feeding Structure for Bandwidth Enhancement" IEEE transactions on antennas and propagation, Vol. 59, no. 2, february 2011.

2. S Bhattacharjee, R. S Kshetrimayum and R Bhattacharjee, "Bandwidth enhancement of printed monopole antennas using magnetodielectric cover" ,IEEE AppliedElectromagnetics Conference (AEMC) 2015.

3. K. Ayyadurai and G.M Muthu, "Bandwidth enhancement of capacitive fed monopole antenna using parasitic patches". International Journal of Microwave and Wireless Technologies 2015.

4. H. Kimouche, D. Abed, B. Atrouz, and R. Aksas," Bandwidth enhancement of rectangular monopole antenna using modified semi-elliptical ground plane and slots",Microwave and Optical Technology Letters, 52(1), 54-58.2010.

5. M. R. Ahsan, M. T. Islam, M. Habib Ullah, and N. Misran, "Bandwidth Enhancement of a Dual Band Planar Monopole Antenna Using Meandered Microstrip Feeding" The Scientific World Journal, 2014, 1-8.

6. Z. Esmati, \& M. MoosaZadeh, "Dual band-notched small monopole antenna with bandwidth enhancement by means of defected ground structure (DGS) for UWB application". Applied Computational Electromagnetics Society Journal, 30(6) (2015).

7. K.P.Ray, S.S.Thakur and S.S Kakatkar, " Bandwidth Enhancement Techniques for Printed Rectangular Monopole Antenna”. IETE Journal of Research, 60(3), 249-256,2014.

8. O..Ahmed., \& A.R.Sebak, "A Printed Monopole Antenna With Two Steps and a Circular Slot for UWB Applications”. IEEE Antennas and Wireless Propagation Letters, 7, 411-413,2008.

9. P.S.Bakariya , S.Dwari and M.Sarkar , "Triple band notch UWB printed monopole antenna with enhanced bandwidth" Int. J. Electron. Commun. (AEÜ) 69 (2015) 26-30

10. A.Singh and S.Singh , "A novel CPW-fed wideband printed monopole antenna with DGS" Int. J. Electron. Commun. (AEU) 69 (2015) 299-306

11. P. Chaudhary and A. Kumar.,"Compact ultra-wideband circularly polarized CPW-fed monopole antenna” Int. J. Electron. Commun. (AEÜ) 107 (2019) 137-145

12. A. A. Adam , S.K.A.Rahim ,K.G.Tan and A.W.Reza,"Design of 3.1-12 GHz Printed Elliptical Disc Monopole Antenna with Half Circular Modified Ground Plane for UWB Application" Wireless Pers Commun (2013) 69:535-549

13. R. Eshtiaghi, R. Zaker, J. Nouronia, and C. Ghobadi , “ UWB semi-elliptical printed monopole antenna with sub band rejection filter" Int.J.Electron.Commun.(AEÜ)64(2010)133-141

14. A.Pandey and R.Mirsa, "Compact Dual Band Monopole Antenna for RFID and WLAN Applications " International Conference on Processing of Materials, Minerals and Energy (July 29th - 30th) 2016.

Published By:

Blue Eyes Intelligence Engineering and Sciences Publication

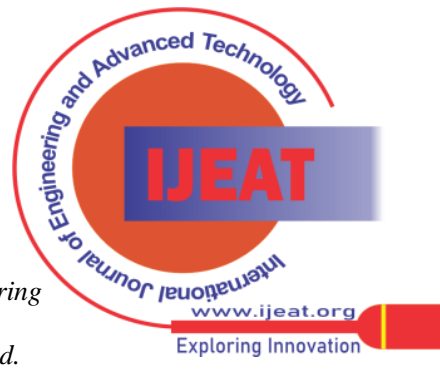


15. S.Kundu," Experiment study of a printed ultra -wideband modified circular monopole antenna ",Microwave Optical Letter,june,2019

\section{AUTHORS PROFILE}

Samom Jayananda Singh received B.E degree in Electronics and Communication Engineering from Anna university Chennai, Tamil Nadu in 2008 and M.Tech in information technology from NERIST, Nirjuli, Arunachal Pradesh, India in 2013. He is currently pursuing Ph.D. with the North Eastern Regional Institute of Science and Technology, NERIST, Nirjuli, Arunachal Pradesh, India. His research interests include phase array antennas, switched multibeam antenna arrays, adaptive arrays, dielectric resonator antennas, metamaterial antennas, horn antenna, direcional antennas and microwave components development for wireless communications systems.

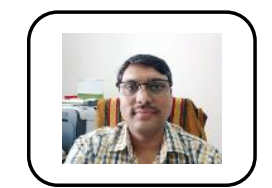

Rajesh kumar , received B.E degree in Electronics and Communication Engineering from the Banglore University ,Bangalore ,Karnataka India, in 2001. He completed M.Sc(Engg) in control system from NIT,Patna in 2007. and Ph.D. in electronics and communication engineering from Jamia Milia Islamia, New Delhi in 2012. He is currently working as an Associate Professor in the Department of Electronics and Communication Engineering, at North Eastern Regional Institute of Science and Technology, (NERIST), Nirjuli, Arunachal Pradesh, India. His research interests are in the area of wireless communication, Fading Channels, Image Processing, Signal Processing, Antennas array, Millimeter-wave antennas. He published over 50 scientific papers in research journals, international and national conferences.

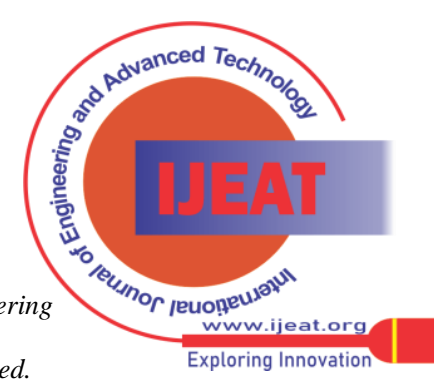

